THURSDAY, JUNE 9, I88I

\section{THE STEPHENSON CENTENARY}

G

EORGE STEPHENSON was born June 9, I78I. The importance of this event to us who now inhabit civilised countries is certain; for whatever view we may take as to the inevitability of railways, it is matter of history that for twenty-five years- 1815 to 1830 -after Stephenson had to all intents perfected the system of railway and locomotive, which still holds its own, no other engineer or competent mechanic went even so far as to admit its merit. It is therefore to George Stephenson that we are indebted for our existing railways, for the immense extension of mechanical contrivance which has followed in their train, and for all that these have done for us in the way of improving the circumstances of life.

As the custom of centennial celebrations has become almost universal, it would partake of irreverence to allow the hunclredth anniversary of the birth of one who has given us so rnuch to pass unnoticed. But in what form can we celebrate such an event? No oratory can remind us of Stephenson's name when we continually hear the puffing of his engine. What monument can compare with the cuttings and embankments seen whichever way we turn? In truth Stephenson's works are ever before the eyes and sounding in the ears of all people. We have no political or social purpose to serve by a national ceremony. Killingworth or Newcastle will have its dinner and, as we understand, the intention is that some money should be subscribed for an educational foundation. 'This is all very well, but it is confined to a few who take a special interest in the place, and is no measure of that universal offering to the memory of our hero which goes up, not once in a hundred years, but hourly.

To the readers of NATURE who are not only of the travelling public, but to whom doubtless the works of Mr. Smiles are familiar, anything we can say as to the life and work of Stephenson must seem totally inadequate. But not to let the occasion pass we will endeavour, by reference to some of the features of Stephenson's work, to illustrate a thought which has recurred to us with everincreasing force when considering the works of those who have pioneered the way in practical mechanics. This thought may be expressed somewhat as follows:-That if we are to accept the proved ability to predict results with certainty as conclusive evidence of a knowledge of the laws and principles on which these results depend, then it is evident that acute observation of mechanical and physical phenomena does lead to a very clear insight into the laws and principles involved, although the observer may be-generally has been-altogether unable, save by the prediction of results, to give definite shape to his abstract ideas, and much more to give them articulate expression. And further, that this apprehension of principles, acquired by the observation of the dependent phenomena, is the only real apprehension, and is a very different thing from that knowledge or conviction of the truth of principles which comes from reading or argument, and which, however useful for purposes of criticism, rarely if ever leads to a prediction.

Vol. XXIV.-No. 606
In the instance of Stephenson we have a perfect example. He received absolutely no education except by his own observation of the animals and other works of nature in the vicinity of his dwelling, and the rude mechanism of the surrounding collieries. Such too were the exigencies of his existence, that although he was assiduous in the task of self-instruction, as in all other things, in 1815 , at the age of thirty-four years, and at the very time when he was making his first engines, "Blucher" and "Puffing Billy," the first of a race destined to overrun the earth and create the greatest of all revolutions, though he could read and write he had not as yet mastered the rule-of-three. Yet in the construction of these very engines he showed his confidence in results, the prediction of which shows that he had acquired an insight into principles which were entirely unexpressed at that time, and as regards some of which their expression is still incomplete.

Amongst the mechanism of the railway, almost every detail of which was conceived by Stephenson, there are certain details or features which, with a view to rescue them from being altogether claimed for other inventors, the friends of Stephenson have ever marked as bearing more distinctly the impression of Stephenson's hand. These are the smooth driving-wheel, the chimney blast, and the multitubular boiler. This is as it should be.

But, as it seems to us, in thus bringing into prominence the special features of Stephenson's system, Stephenson's friends have effectually diverted attention from that which is of far more importance. Thus, although it has never been claimed for Stephenson that he was the first to use smooth driving-wheels, Trevithick and Hedley having been obviously before him, it is contended that Stephenson consistently from the first maintained the sufficiency of the adhesion, while the others invented "imaginary difficulties" which led them to contrive all sorts of means of preventing the wheels of their locomotives from slipping. This view of the matter is however essentially wrong, and is unfair to both sides, for on the one hand, while there is no evidence to show that Trevithick or Blenkinsop ever ignored the tractive power of smooth wheels, neither is there any evidence to show that Stephenson ever maintained that the adhesion of smooth wheels would suffice to accomplish that for which the rack was being used. Had he done so he would have been wrong. But, on the contrary, there is ample evidence to show that Stephenson clearly perceived-that at the very onset he determined by careful experiment-the limit of the adhesion of his smooth wheels, and that he never attempted to use them except on a level road. The question at issue is much broader and more important than that of mere mechanical contrivance. It was as to how far the locomotive should be set to the task of the horse in drawing its load over the hills and valleys, and how far the hills should be cut down and the valleys filled up.

This, the level road, the very form of the railway, was Stephenson's main idea. And it was his foresight and determination in respect of this that made his railways a success from the first. His experience and observation had led him to perceive what all subsequent experience has confirmed, that the locomotive, in virtue of its size and clumsiness, could only be usefully employed on a nearly level railway. He did not actually maintain that 
it would be impossible to make a machine that would travel on common roads and even mount hills, but " even suppose that such a machine could be constructed to carry twenty or thirty passengers at ten miles an hour, put it on a level railway and it would carry 200 or 300 passengers at thirty or forty miles an hour."

In his first colliery railways at Killingworth and Hetton he laid the lines in a series of flat reaches separated by inclines, and working the inclines by fixed engines, confined the functions of the locomotive to drawing the waggons along the flat reaches. It was this insistence on the level road that enabled him to use smooth wheels, and not that he had discovered any adhesion previously unknown or that others had overlooked.

Stephenson's position was a nearly level line at any price on waich the adhesion of the wheels is sufficient as against a road following the slope of the country, for which, according to his view, by whatever means the adhesion might be increased, the iron horse was ill adapted. In the clear conception of the importance of this level road, coupled with his determinate insistence in carrying out his view, no matter what the difficulty - the veritable removal of mountains-have we not the best of all proof that, however unconsciously, he was guided by a perception of that law which connects the limits in size and activity of structures, with the strength of the material of which they are composed. And by which law we may now perceive that it is only by smoothing the road and so reducing the call for strength and power that we have made our machines to exceed in size and speed the limits which Nature had reached in her animals.

Into another law, called the Conservation of Energy, there can be no doubt that Stephenson had an insight far beyond his time. He saw that the conveyance of a load was not a question of force, but of the product of force into the distance traversed, and that however great might be the tractive power of his engine, its speed must depend on the ratio of the rate at which steam could be generated to the load. So long therefore as the tractive power was so large as-compared with the steam-generating power of his boiler-to prevent his engine, when fully loaded, travelling at more than ten miles an hour, he could gain nothing by increased adhesion. But, on the other hand, in his first engine the desideratum was increased steam-generating power for the same weight of boiler.

With, as Robert Stephenson has told us, the direct object of accomplishing this, George Stephenson turned the exhaust steam in the form of a jet or blast up the chimney of his second locomotive, "Puffing Billy." If this is so, and there appears no evidence to the contrary, it was a prediction with regard to the motion of fluids, for the making of which there is as yet no established law in the theory of hydrodynamics. That the result is such as was here predicted, or that a jet of steam or of air playing at high velocity along the interior of an openended tube does impart motion to the air within the tube and causes a current, is of course now well known, but our present knowledge is derived from the experience of the locomotive chimney. There is no evidence that it was known to any one before $181_{5}$, nor indeed has there been found any other mechanical purpose of general importance in which the same action could be usefully employed. Neither in the stationary engine nor yet in the marine engine has it proved economical. Thus the locomotive and its offspring, the portable engine, were the only machines possessing this organ.

Although it has been the custom for writers on the steam-engine to speak as though the manner of action of the blast were self-evident, this only shows that these authors have not understood it-indeed how should they? The general law on which the action of the blast depends is that a jet of fluid issuing into surrounding fluid at rest will not, when it has more than a certain velocity, proceed in a straight vein or column, but begins at once to wriggle, and as it advances involves itself in an extremely complex manner with the surrounding fluid, with which it shares its forward momentum. It is only during the last few years that the generality of this action and the circumstances on which it depends have attracted attention, and the completeness with which the action has been overlooked is shown by the numerous attempts that have been made to invent fanciful explanations of the following phenomenon. When a jet of steam, say half an inch in diameter, issues from a high-pressure boiler, as from a gauge cock, although the steam itself must have the temperature of boiling water, still the hand may be held in the jet at a distance of two or three inches from the cock without any inconvenience. How has the temperature of the steam become lowered ? is the question for the answering of which numerous hypotheses have up to quite recently been invented. The answer is that the temperature of the steam does not become lowered, any more than the strength of the mustard in a sandwich, but that the steam has involved within its column layers of cool air, sandwich fashion, and as the combination rapidly passes the same point of the skin, the sensation produced is that of the mean temperature of the air and steam.

It is on this action of a jet to mix itself up with the surrounding medium that the draught produced by the blast up the chimney depends, and Stephenson's confident prediction of this draught is the best evidence that observation had led him to a perception of the more general action.

Considering the capacity of the man as shown by his other work, it would have been a matter for surprise had not Stephenson acquired a unique knowledge of the phenomena of fluid motion. He had the best opportunity for observation-his whole time had been spent in the care of pumps, pumping-engines, and the arrangements for ventilating and draining mines. His habit was to bring all his ideas at once to the test of experiment; and in devising his safety-lamp he had carried out a very careful series of experiments on the behaviour of jets and the rate of their admixture with the surrounding air.

Although, as shown by the employment of the multitubular boiler, Stephenson's mechanical insight does not perhaps stand out in so very clear a light, inasmuch as he made this step at the suggestion of Mr. Booth, still it cannot have been fortuitous that in adopting these small tubes he should have at once introduced all those conditions on which their employment is alone successful.

That small tubes of the same aggregate capacity as a single flue afford greater cooling surface for the hot gases is indeed obvious, but it was Stephenson's own observation that taught him that such increase was desirable, 
while the fact that the gases in passing through the small tubes would encounter much greater resistance than in the single flue rendered the successful employment of the multitubular boiler dependent on the increased action he could give to the blast. However in all respects he came out right in the very first trial.

In the "Rocket" he had a self-moving machine, which resembled the moving animal not only in the fact that they both derived their power of motion from the combustion of carbon, but the physiology of the machine resembled that of the animal system in that essential particular which connects the action of the heart and lungs with that of the muscles, so that any demand upon the activity of the latter is at once met by increased activity in the former. In the locomotive the law of adjustment is perfect. Whatever the load within the limit imposed by the adhesion of the wheels, and whatever the speed, the stimulating action on the fire is sufficient, and no more than sufficient, while in all cases the tubes are sufficiently long, and no more, to pass the heat generated into the boiler.

The functions of the locomotive engine more nearly correspond with the functions of moving animals than do the functions of any other machine, and hence it was essential that there should be a correspondence between the organisation of the locomotive and that of working animals, which correspondence may be dispensed with in other engines. Is it not probable, we ask, that he who produced the locomotive physiologically complete had been guided, however unconsciously, by the truth of his observation of those animals which his machine was to set free from their task?

OSBORNE REYNOL.DS

\section{THE HISTORY OF SALT}

The History of Salt. By Evan Marlett Boddy. (London : Baillière, Tindall, and Cox, I88I.)

THIS book is quite a literary curiosity: the author hopes, and not without reason, that it will be found to afford amusement. Mr. Boddy we take to be a medical student, and it is a kindness to him to suppose that he is young. After reading the first half-dozen pages of his work the idea gradually dawned upon us that he intended it for an elaborate joke, very much after the manner, we should suppose, of Mr. Benjamin Allen and Mr. Robert Sawyer, had those gentlemen been tempted to follow the paths of literature. But, adhibenda est in jocando moderatio, and never more so than when the joke is at the expense of a venerable parent. In dedicating his work to his father Mr. Boddy, for the credit of human nature, must be acquitted of the charge of a conscious joke, otherwise such an instance of filial disrespect would be without parallel.

This astonishing production owes its origin to a letter advising total abstention from salt, which had appeared in a temperance journal, and the author felt himself constrained, for the good of humanity, to deliver himself of the succession of "farcical puerilities" and "whimsical crudities" which make up the "imaginative plerophory" "redundant of inane folly and trivial hyperbole" of his book. The words in italics are Mr. Boddy's; he of course applies them to the opinions of other people. With the sanction of Vespasian's law, that it is unlawful to give ill language first, but civil and lawful to return it, we think ourselves justified in applying them to Mr. Boddy's book. And how richly that book merits them we proceed to make abundantly clear, and on the author's own showing.

Mr. Boddy is too hard upon the unfortunate letterwriter in the journal of temperance: he is not even grateful to him as the remote cause of the existence of his own book. The letter-writer, "with amusing selfcomplacency, accused it [salt, not temperance] of producing evils of an astounding nature-such is the latitude of pragmatical ignorance and silly egotism. The palpable absurdity of such an argument must be apparent even to the most careless thinker : it is with the view of exposing such a fallacy, both injurious and irrational, that I have written this treatise." One is tempted to ask--If the argument is so palpably absurd, even to the most careless thinker, why in the world has Mr. Boddy taken the trouble to write his treatise?

It does not seem to be generally known what would happen to a world devoid of salt ; such, according to $\mathrm{Mr}$. Boddy, is the "dense obtenebration with which the subject is surrounded." The picture of a saltless world, as drawn by our author, is something awful to contemplate. Nothing but the thought of "our ignorant conceits," our "unaccountable obliquity of judgment," and "the apathetic indifference" with which we have hitherto looked upon the humble condiment which has graced our tables " in the smallest receptacles, as if it were the most expensive article," and to which we, "in the most finical, grotesque manner," help ourselves "in almost infinitesimal quantities, as if it were a mark of good breeding and delicacy," would compel us to reveal the "imaginative plerophory." The nervous reader will be pleased to fortify himself with at least a teaspoonful of the condiment before he begins its perusal.

"Were the human race once deprived of the chloride of sodium, even for a limited period of time, we should not only lose a natural healthful incentive for our food, but disease, with all her attendant miseries, would spread with such relentless impetuosity as would defy, and even paralyse, the efforts of the most skilful physician, the ingenuity of the surgeon, and the scientific improvements and hygienic precautions of the sanatarian. The strength and vigour of manhood would fade as if blasted by disease, food would act as a poison, the blood would not be replenished with the salt which it requires, and consequently our skins would soon be covered with corruption, our cattle would die, our crops would be nipped in the bud, the air would be full of offensive insects, the soil would become foul and barren, the sea a waste of stagnant waters, and all the beautiful productions of nature would wither and decay, and our glorious earth would degenerate into a hideous solitude, solely inhabited, very probably, by monsters horrible to behold, more repulsive than those gigantic reptiles which once roamed by the dreary marshes of an incomplete world."

And yet, according to Mr. Boddy, "the English working classes are nearly, if not altogether, unacquainted with the benefit of salt": "at the tables of the wealthy it is perfectly absurd to see the small amount which is used." We are not even allowed the poor consolation of knowing that in our false economy we are unwittingly conserving our choicest blessing. "We do not diet ourselves as we should: in this respect we are far behind the veriest 